\title{
Recent progress in vaccine development against Leishmania species infections
}

\author{
Barbara Papadopoulou PhD, Martin Olivier PhD, Marc Ouellette PhD
}

\begin{abstract}
B Papadopoulou, M Olivier, M Ouellette. Recent progress in vaccine development against Leishmania species infections. Can J Infect Dis 1999;10(Suppl C):9C-15C.

The understanding of the immunobiology of infections caused by the protozoan parasite leishmania is now extensive and has pinpointed the importance of $\mathrm{T}$ cell-mediated immunity. Several vaccination strategies using either killed parasites, subunit vaccines, DNA vaccines or live attenuated strains have been used successfully with and without adjuvants to induce cellular immunity and protect against leishmania infections. The most recent progress in leishmania vaccine development is described.
\end{abstract}

Key Words: Leishmania; T cell-mediated immunity; Vaccine development

\section{Progrès récents dans le développement d'un vaccin contre les infections aux espèces de Leishmania}

RÉSUMÉ : La compréhension de l'immunobiologie des infections causées par le protozoaire parasite leishmania est désormais substantielle et a précisé l'importance de l'immunité médiée par les lymphocytes T. Plusieurs approches vaccinales faisant appel à des parasites tués, à des vaccins à sous-unités, à des vaccins à l'ADN ou à des souches vivantes atténuées ont été utilisées avec succès avec et sans adjuvants pour induire une immunité cellulaire et une protection contre les infections à leishmania. On décrit les progrès les plus récents survenus dans la mise au point d'un vaccin contre leishmania.

$\mathrm{T}$ he protozoan leishmania is the cause of a wide spectrum of diseases in humans and domestic animals. The clinical manifestations of leishmaniasis vary with the species, encompassing cutaneous leishmaniasis (oriental sore), mucocutaneous leishmaniasis (espundia) and visceral leishmaniasis (kala-azar), the most severe form of the disease, which is often fatal if untreated. The flagellated promastigote leishmania is transmitted to humans by the phlebotomine sand fly. After its ingestion and entry into the phagolysosome of the host macrophages, the promastigote differentiates into the aflagellated amastigote, which then replicates within the macrophage. Leishmania are distributed worldwide, and between 10 and 15 million people are estimated to be infected, with 400,000 new cases reported every year (1). More than one- third of the world's population lives in endemic areas and is at risk of contracting an infection (2). Increases in travel and intervention in regional conflicts such as 'Operation Desert Storm' (3) have increased the number of leishmania cases in nonendemic areas. The incidence of leishmaniasis is also rising because of the lack of vaccines, difficulty of vector control and increased resistance to chemotherapy (4). Leishmania has also emerged as a serious opportunistic pathogen in human immunodeficiency virus (HIV)-infected humans, and several cases have been reported around the Mediterranean littoral (5).

There have been few, if any, vaccines for the treatment of protozoan parasites that infect several hundred million people worldwide and are the cause of substantial morbidity and mortality. Several reports have suggested, however, that vac-

Centre de Recherche en Infectiologie, Université Laval, Ste-Foy, Québec

Correspondence and reprints: Dr Barbara Papadopoulou, Centre de Recherche en Infectiologie, CHUQ, Pavillon CHUL, 2705 boul Laurier, RC-709, Ste-Foy, Quebec G1V 4G2. Telephone 418-654-2705, fax 418-654-2715, e-mail Barbara.Papadopoulou@crchul.ulaval.ca 
cination may be useful in the control of leishmaniasis, and several approaches have been attempted (2). Before discussing the different strategies to generate an antileishmanial vaccine, it is important to outline the requirements for the development of an effective protective immunity against this parasite.

\section{PROTECTIVE IMMUNE EFFECTOR MECHANISMS NECESSARY FOR RESOLVING LEISHMANIA INFECTIONS}

Leishmania metacyclics bind macrophages to cell surfaces through numerous receptors, but in physiological conditions the main ones appear to complement receptors type I (CR1) and type III (CR3). These receptors bind to complement components attached to the plasma membrane of the parasite (6). Once internalized into phagosomes, leishmania transform into amastigotes, the developmental form in which they remain in the vertebrate host. Amastigotes replicate by binary fission, eventually rupturing macrophages, and invade uninfected cells probably via the FCIg and CR3 receptors (7). Normally, phagocytosis of intracellular pathogens induces macrophages to produce cytokines, chemotactic factors such as chemokines, activating and modulatory factors, and hematopoietic-stimulating factors; however, in the case of leishmania infection, the entry of the parasite into macrophages is relatively silent and generally occurs in the absence of macrophage-derived cytokines (8). It has been shown that major histocompatibility complex (MHC) class II molecules are localized in the membrane of the parasitophorous vacuole, suggesting a mechanism by which the immune response to this pathogen becomes class II and CD4+-dependent (9). Thus, intracellular compartmentalization of leishmania is responsible for the presentation of peptide antigens in the context of MHC class II molecules, which are recognized by CD4+ T cells.

Experimental murine leishmaniasis has been studied extensively for the past decade and has provided one of the first examples of the importance of $\mathrm{T}$ helper type 1 and $\mathrm{T}$ helper type 2 (Th1/Th2) cell subsets in the development of the disease. In murine leishmaniasis, the genetically resistant C57BL/6 mice display a Th1 response, whereas the susceptible $\mathrm{BALB} / \mathrm{C}$ mice develop a clear Th2 phenotype (8). T cell lines isolated from mice vaccinated with various soluble fractions of leishmanial antigens have shown that Th1-producing interferon-gamma (IFN- $\gamma$ ) and interleukin-2 (IL-2) transferred protection, whereas cells of Th2 lineage that produced IL-4, IL-5 and IL-10 exacerbated disease $(8,10,11)$. It is important to emphasize that resistance and/or susceptibility to leishmania infection in the murine model system appears to be controlled by several mechanisms that will be briefly discussed here.

Resistance to leishmania infections is associated with the induction and expansion of a discrete subset of $\mathrm{CD} 4^{+} \mathrm{T}$ cells, designated Th1, that are restricted by MHC class II and produce IFN- $\gamma(8,12)$. IFN- $\gamma$ activates the inducible nitric oxide synthase in macrophages, leading to the production of reactive nitrogen radicals that are toxic for the parasite (13). IFN- $\gamma$ plays a key role in the control of Leishmania major infection. It has been shown that mice with disrupted genes for IFN- $\gamma$ or IFN $-\gamma$ receptor failed to resolve their lesions $(14,15)$. IL-12 also favours Th1 cell development through its capacity to stimulate IFN- $\gamma$ production by Th1 cells (16) and is crucial for cure. Mature Th1 cells could, thus, expand in number and release more IFN- $\gamma$, which increases IL-12 production by the macrophages. It is possible that IL-12 is produced by macrophages upon leishmania infection and that it induces Th1 cells to secrete IFN- $\gamma$. Both IL-12 and IFN- $\gamma$ may drive CD $4+$ T cell differentiation towards the Th1 lineage (17) and are required for effective resolution of leishmaniasis (18). The essential role of IL-12 in Th1 development has been confirmed by results showing that neutralization of IL-12 or deletion of the IL-12 gene in resistant mice led to the development of a Th2 response after leishmania infection $(18,19)$.

In contrast, susceptibility to leishmania is characterized by a Th2 response, which produces predominantly IL-4. This cytokine promotes high antibody titres directed towards the parasite but does not activate macrophages for parasite killing. Cytokines produced by Th2 cells exert a macrophage deactivating function. IL-4 has been shown to hamper the activation of macrophages induced by IFN- $\gamma$ and to suppress the up-regulation of the gene for interferon regulatory factor 1 (20). Several reports support the crucial role of cytokines in directing $\mathrm{CD}_{4}{ }^{+} \mathrm{T}$ cell differentiation and, consequently, the outcome of the disease. Macrophages pre-incubated in vitro with cytokines before infection with leishmania acquired the capacity to kill the intracellular parasites (21). Moreover, cytokines such as IFN- $\gamma$, tumour necrosis factor-alpha (TNF- $\alpha$ ), IL-12 and granulocyte-macrophage colony-stimulating factor (GM-CSF) have been used as antileishmanial therapy in experimental models (22-26) and in human Leishmania donovani infection (27).

Natural killer (NK) cells have also been suggested to play a role in the development of a Th1 response by secreting IFN- $\gamma$ at early stages following leishmania infection, and it has been shown that depletion of NK cells in resistant mice favours parasite multiplication (28). Accessory molecules such as the CD40 cell surface molecule (CD4OL) on activated $\mathrm{T}$ cells have also been shown to be necessary for the generation of a protective cell-mediated immune response to leishmania, presumably via its interaction with the CD40 receptor (CD4OR) on primed monocytes/macrophages, which induces IL-12 secretion (29). Resistant mice deficient in either the CD40 or its ligand molecules failed to generate a Th1 response and were unable to control infection $(30,31)$. It is, therefore, possible that during infection of resistant mice strains, macrophages present leishmanial antigens to T cells, resulting in CD4OL activation, which in conjunction with IFN- $\gamma$ induces IL-12 production by the macrophages (30). CD40L may also have a direct effect on the synthesis of nitric oxide (32). Several studies have reported that antigen-specific $\mathrm{CD}^{+} \mathrm{T}$ cells are similarly important in the resolution of cutaneous and visceral infections $(33,34)$. However, it is unclear how these cells execute this function because results from several investigations attempting to demonstrate recognition of leishmania-infected 
TABLE 1

Live or killed parasites, antigens and adjuvants for vaccination against leishmaniasis

Killed polyvalent leishmania promastigotes (reference 40)

Killed leishmania promastigotes + BCG (references 41,42,74)

BCG (reference 75)

Low parasite dose (references 43,44)

$\mathrm{T}$ cell antigens (reference 76 )

Membrane antigens into liposomes (references 77,78 )

Amastigote antigens (A2,P4,P8) (reference 52)

Leishmanial antigens + interleukin-12 (adjuvant) (references 72,79)

Synthetic lipopeptides (gp63 epitopes) (reference 80)

Anti-CD40 mAb (reference 81)

Cytotoxic gene expression (reference 45)

BCG Bacille Calmette-Guérin; gp63 Glycoprotein 63

macrophages by $\mathrm{CD}^{+} \mathrm{T}$ cells have been contradictory. Recent data by Huber and colleagues (35) have shown that CD ${ }^{+} \mathrm{T}$ cells are not required for the long term control of a primary infection with $L$ major.

The humoral immunity induced by many viral and bacterial vaccines mediates protection that is maintained over a long period of time. In contrast, for other intracellular infections such as with $L$ major for which cell-mediated immunity is required for protection, the mechanisms for developing durable responses after vaccination have not been well defined. A critical question is whether prophylactic vaccination requires exclusively the induction of a Th1 response to protect against leishmanial infections or whether the prevention of a Th2-type response is also needed. It has been recently suggested that generation of a protective immunity is dependent on the induction of an exclusive Th1 response and, most importantly, that the Th2 cell development has to be blocked (36). Generation of long term protective immunity against leishmaniasis must induce memory T cells, which in the presence of the parasite are stimulated to secrete protective Th1 cytokines.

\section{VACCINATION STRATEGIES AGAINST LEISHMANIASIS}

Several observations suggest that vaccination may be feasible in the control of leishmaniasis caused by the protozoan leishmania. For example, some leishmania skin infections, such as old World cutaneous leishmaniasis, have a propensity to be self-limiting. Cure is followed by long-lasting immunity against reinfection. Furthermore, protective immunity also appears to develop in successfully treated kala-azar patients, suggesting that sterile immunity may be established following first contact with the parasite. The traditional practice of leishmanization, performed either by exposing certain areas of the skin to sand fly bites or by scratching the skin area with infected material, has shown certain protection against reinfection but is not widely accepted because of disease complications that have recurred in some patients (2). Overall, the experience supports the notion that a vaccine against leishmaniasis is a reasonable possibility.
TABLE 2

Subunit antileishmanial vaccines

Glycoprotein 63 (references 47,82)

Promestigote surface antigen 2 (reference 83)

T cell LACK antigen + interleukin-12 (reference 49)

Thiol-specific antioxidant protein (reference 84)

Experimentally, avirulent, temperature-sensitive mutants obtained by chemical mutagenesis, lethally irradiated or heat killed, or soluble extracts of promastigotes have been used successfully in immunizing mice against cutaneous leishmaniasis (37-39). First-generation vaccines based on killed parasites with or without adjuvant have reached various stages of phase I, II or III trials in humans (2) (Table 1). In Venezuela, over 16,000 individuals have been vaccinated with killed Leishmania mexicana and/or Leishmania braziliensis with or without Bacille Calmette-Guérin (BCG) (2). In Brazil, efforts to develop a nonliving promastigote vaccine against American cutaneous leishmaniasis have been made by using killed polyvalent promastigotes derived from Leishmania mexicana, Leishmania amazonensis, Leishmania guyanensis and Leishmania braziliensis (40). Vaccinated individuals in the above studies showed an enhanced level of IFN- $\gamma$ production and $\mathrm{CD}^{+}{ }^{\mathrm{T}}$-specific cells. In a recent study in Ecuador, over $70 \%$ of vaccinated children with killed leishmania promastigotes of three strains (L braziliensis, L guyanensis and L amazonensis) combined with BCG were protected from cutaneous leishmaniasis (41). Two recent vaccine trials in Iran with killed $L m a$ jor promastigotes plus BCG were encouraging, but showed lesser efficiency relative to the incidence of the disease (42). Live parasites have also been used for vaccination, administered either in a low dose $(43,44)$ or as recombinant parasites expressing a cytotoxic gene (45). Both studies have demonstrated a protective immune response in susceptible $\mathrm{BALB} / \mathrm{C}$ mice against infectious challenge.

Fractionation is an improvement over using the whole parasite in terms of both standardization and reduction of unwanted side effects, and effective immunization against leishmaniasis. Leishmanial antigens, either coated with lipids or uncoated, or in the presence of adjuvants or not, as well as $\mathrm{T}$ cell antigens, have been used as vaccines mainly in murine experimental systems (Table 1). Second-generation vaccine candidates, including recombinant molecules that constitute major components of the parasite membrane such as glycoprotein 63 (gp63) or glycoprotein 46 (gp46), have been tested in an experimental murine system (Table 2). An oral recombinant gp63 vaccine (46) was shown to confer protective immunity against cutaneous leishmaniasis (47), and an improved version of this vector conferred considerable cross-resistance to $L$ donovani (48). The leishmania-specific $C D 4^{+} \mathrm{T}$ cell LACK antigen administered as a recombinant protein has been shown to transfer protection against $L$ major in susceptible BALB/c mice (49). T cells generated during the cure of leishmanial infections in humans recognize a broad range of leishmanial antigens, suggesting that although single-molecule 
TABLE 3

DNA vaccines

Glycoprotein 63 (references 53,85)

LACK Ag \pm interleukin-12 (reference 56,86)

Prometigote surface antigen 2 (reference 36)

\section{TABLE 4}

Live recombinant attenuated vectors as vaccines

Salmonella-gp63 (references 48,82,87)

Salmonella typhimurium-gp63 + tetanus toxoid Ag (reference 88)

Salmonella typhimurium-TNF- $\alpha$ IFN- $\gamma$ or IL-2 or MIF (reference 89 )

BCG-gp63 (references 90,91)

Vaccinia-gp46 (references 92)

BCG Bacille Calmette-Guérin; gp46 Glycoprotein 46; gp63 Glycoprotein 63; IFN- $\gamma$ Interferon-gamma; IL-2 Interleukin-2; TNF- $\alpha$ Tumour necrosis factor-alpha; MIF Migration inhibitory factor

vaccines such as gp63 or lipophosphoglycan have success in inbred mice, the search for a single major protective antigen for vaccination against disease in humans may be fruitless (50). Polymorphism for MHC class I and II molecules on the surface of infected cells in genetically diverse human populations also makes a single-antigen vaccine less attractive because some members of the population may fail to bind the antigen for presentation to T cells (51). However, as Soong et al (52) reported, this may be different with the use of a multiple amastigote antigen vaccine.

The protease gp63 has also been administered as a DNA vaccine, and a Th1 response was found to be associated with protection in vaccinated mice (53) (Table 3). Immunization with plasmid DNA has been shown to induce protective immunity in a variety of experimental systems through both $\mathrm{MHC}$ class I- and class II-restricted T cell responses $(54,55)$. Vaccination with DNA encoding the immunodominant LACK parasite antigen also confers protective immunity to mice infected with $L$ major (56), and protection seemed to be associated with IL-12 production. Similarly, vaccination with promastigotespecific antigen 2 DNA can protect mice against $L$ major infection by developing a Th1 type response (36).

Live recombinant attenuated vectors are widely used for vaccination as vehicles to express immunogenic proteins from several pathogens. Genetically or naturally attenuated microbes such as salmonella, BCG and vaccinia-expressing leishmanial antigens, toxins or cytokines have been administered as vaccines in murine experimental systems (Table 4). Attempts to generate live attenuated leishmania strains for vaccination purposes have also been recently undertaken. Our ability to introduce stable new genes and disrupt or delete endogenous ones has provided the tools necessary to generate genetically less virulent or avirulent parasites that may be used as safe live vaccines for protozoal diseases. Development of live parasites attenuated by molecular means has been a driving force in the recent years (Table 5). Null mutants by gene targeting have been generated in L major (dhfi-ts [57] hsp100, [58], and L mexicana (cysteine proteinase gene
TABLE 5

Inactivation of leishmania target genes for vaccination purposes

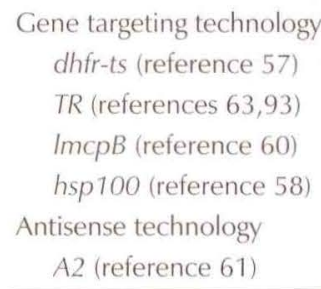

[lmcpb] [59]). Parasites in which a large cluster of cysteine proteinase genes were replaced by gene targeting were found to be less virulent and to confer protection against challenge (60). Using antisense RNA against the amastigote specific $L$ donovani $A 2$ gene, parasites became less virulent and animals were protected against challenge (61). Disruption of the $L$ major hsp 100 gene has resulted in markedly delayed lesion development in mice (58). Although encouraging, protection was often not perfect and a minor population of the parasites was reverting to virulence, indicating that further work is required $(60,61)$. We have disrupted the gene encoding for trypanothione reductase (TR), an enzyme keeping trypanothione into its reduced form (62). The pivotal role of TR in oxidative stress management suggests that it might be an attractive target for the production of avirulent strains. Attempts to yield a null mutant for the TR gene obtained a TR trisomic mutant with two alleles successfully disrupted by the two selectable markers and a third wild-type allele as a result of genomic translocation (63). The resulting polyploidy strongly suggests that $T R$ gene is essential for leishmania promastigotes. A similar conclusion has been drawn for the dhfr-ts gene (64) and for a cdc2-related kinase (59). Despite that one TR allele was left, susceptible BALB/c vaccinated with a $L$ donovani $T R$ disruption mutant were protected against reinfection with a wild-type $L$ donovani strain. Tovar et al (65) reported similar results more recently.

Other putatively interesting targets for the development of live vaccines against leishmaniasis using gene targeting technologies may be the amastigote-specific genes because their inactivation should alter either the capacity of the parasite to efficiently differentiate or its capacity to survive once inside the phagolysosomes. New targets identified through the ongoing $L$ major sequence project may also be chosen for the generation of live attenuated mutants. Ideally, an attenuated live vaccine should cover a large spectrum of different species because the epidemiology of strains responsible for leishmaniasis is not the same in the New World and in the old World, and, therefore, vaccine composition should change accordingly. Given that $\mathrm{T}$ cell-mediated immunity is required for the development of a protective immune response against leishmania infections, live attenuated vaccines should be ideal candidates for vaccination. Live attenuated vaccines have been used against a number of human and animal pathogens with high efficacy and safety. Several viral $(66,67)$ and bacterial (68-70) pathologies can be prevented efficiently using live 
attenuated pathogens as vaccines. BCG, a naturally live attenuated Mycobacterium bovis strain, is one of the most widely used vaccines in the world, being administered to approximately 100 million children each year. All BCG strains used so far as vaccines are safe (70). Auxotrophic strains of $B C G$ were recently made to obviate potential adverse effects of BCG vaccine in HIV-positive severely immunocompromized individuals (71). Although side effects were not seen in several studies of HIV-seropositive children (71), the safety of live attenuated BCG strains and of other live attenuated vaccine candidates needs to be carefully addressed.

The elaboration of an efficient vaccine involves the generation of short lived effector cells, but also generation of long term protective memory cells. The nature of the cells that confer immune memory against parasitic infections and the mechanisms by which it is obtained are unknown. To assess the requirements for the development of a long term immunity following a leishmania infection, we have developed a suicide-type system based on the expression of the thymidine kinase gene of Herpes simplex virus-1 (tk) gene in leishmania that become hypersensitive to treatment with ganciclovir, and we have tested the potential of using these recombinant parasites as a vaccination approach (45). Mice infected with TKrecombinant leishmania and treated four days later with ganciclovir to clear the parasites that were protected against infective challenge (45).

Adjuvants in vaccines are thought to function in several ways, including targeting of antigens to macrophages, CD4+ $\mathrm{T}$ cell subset differentiation and macrophage activation, but the mechanism(s) by which they act is poorly understood. BCG has often been used in several combinations (Table 1) as adjuvant in the vaccination against leishmaniasis with satisfactory results. Recently, the adjuvant effect of certain cytokines has been demonstrated. Vaccination of BALB/C mice with leishmanial antigens and IL-12 promoted the development of $\mathrm{CD}^{+}$ $\mathrm{T}$ cell response (72), suggesting that $\mathrm{IL}-12$ can substitute for bacterial adjuvants (Table 1 ). In Kenya, IL-12 has been tested in vaccination experiments in primates (73). In other cases IL-2, IFN- $\gamma$ and TNF- $\alpha$ have been expressed by recombinant attenuated bacteria and tested as vaccines against $L$ major infections (Table 4). We have also tested the potential of expressing cytokine genes by the parasite to induce macrophage activation. GM-CSF-expressing leishmania were used to infect BALB/C mice, and the overproduction of this cytokine seems to control the level of infection during the first weeks.

\section{CONCLUSIONS}

In recent years, considerable progress has been made concerning the understanding of the immunobiology of leishmania infections, in the genetics of leishmania and in the isolation of parasite surface molecules. This knowledge has been used to develop ingenious and effective strategies for vaccination against leishmaniasis. With further basic and clinical research, it is possible that for the first time an effective vaccine will be available for an intracellular parasite.

ACKNOWLEDGEMENTS: This work is supported by the Canadian University Research Program of Pasteur Mérieux Connaught and the Medical Research Council-University Industry Program, and by Medical Research Council Group Grant gr4500 in Infectious Diseases. Drs B Papadopoulou, M Oliver and M Ouellette are a Medical Reseach Council scholar, a Fonds de Recherche en Santé du Québec scholar and a Medical Reseach Council scientist, respectively. Drs M Olivier and M Ouellette are recipients of the Burroughs Wellcome Fund New Investigator Award in molecular parasitology.

\section{REFERENCES}

1. Ashford RW, Desjeux P, deRaadt P. Estimation of population at risk of infection and number of cases of leishmaniasis. Parasitol Today 1992;8:104-5.

2. Modabber F. Vaccines against leishmaniasis. Ann Trop Med Parasitol 1995;89(Suppl 1):83-8.

3. Magill AJ, Grogl M, Gasser RA Jr, Sun W, Oster CN. Visceral infection caused by Leishmania tropica in veterans of Operation Desert Storm. N Engl J Med 1993;328:1383-7.

4. Ouellette M, Papadopoulou B. Mechanisms of drug resistance in leishmania. Parasitol Today 1993;9:150-3.

5. Alvar J, Canavate C, Gutierrez-Solar B, et al. Leishmania and human immunodeficiency virus coinfection: the first 10 years. Clin Microbiol Rev 1997;10:298-319.

6. Mosser DM, Rosenthal LA. Leishmania-macrophage interactions: multiple receptors, multiple ligands and diverse cellular responses. Semin Cell Biol 1993;4:315-22.

7. Guy RA, Belosevic M. Comparison of receptors required for entry of Leishmania major amastigotes into macrophages. Infect Immun 1993;61:1553-8.

8. Reiner SL, Locksley RM. The regulation of immunity to Leishmania major. Annu Rev Immunol 1995;13:151-77.

9. Lang T, de Chastellier C, Frehel C. Distribution of MHC class I and of MHC class II molecules in macrophages infected with Leishmania amazonensis. J Cell Sci 1994;107:69-82.

10. Locksley RM, Heinzel FP, Holaday BJ, Mutha SS, Reiner SL, Sadick MD. Induction of Th1 and Th2 CD4+ subsets during murine Leishmania major infection. Res Immunol 1991;142:28-32.

11. Reed SG, Scott P. T-cell and cytokine responses in leishmaniasis. Curr Opin Immunol 1993;5:524-31.

12. Heinzel FP, Rerko RM, Hatam F, Locksley RM. IL-2 is necessary for the progression of leishmaniasis in susceptible murine hosts. J Immunol 1993;150:3924-31.

13. Assreuy J, Cunha FQ, Epperlein M, et al. Production of nitric oxide and superoxide by activated macrophages and killing of Leishmania major. Eur J Immunol 1994;24:672-6.

14. Wang ZE, Zheng S, Corry DB, et al. Interferon gammaindependent effects of interleukin-12 administered during acute or established infection due to Leishmania major. Proc Natl Acad Sci USA 1994;91:12932-6.

15. Swihart K, Fruth U, Messmer N, et al. Mice from a genetically resistant background lacking the interferon gamma receptor are susceptible to infection with Leishmania major but mount a polarized T helper cell 1-type CD4 + T cell response. J Exp Med 1995; 181:961-71.

16. Seder RA, Gazzinelli R, Sher A, Paul WE. Interleukin-12 acts directly on CD4 + T cells to enhance priming for interferon gamma production and diminishes interleukin 4 inhibition of such priming. Proc Natl Acad Sci USA 1993;90:10188-92.

17. Scharton-Kersten T, Scott P. The role of the innate immune response in Th1 cell development following Leishmania major infection. J Leukoc Biol 1995;57:515-22.

18. Heinzel FP, Rerko RM, Ahmed F, Pearlman E. Endogenous IL-12 is required for control of Th2 cytokine responses capable of exacerbating leishmaniasis in normally resistant mice. J Immunol 1995;155:730-9. 
19. Magram J, Connaughton SE, Warrier RR, et al. IL-12-deficient mice are defective in IFN-gamma production and type 1 cytokine responses. Immunity 1996;4:471-81.

20. Ohmori Y, Hamilton TA. IL-4-induced STAT6 suppresses IFN-gamma-stimulated STAT1-dependent transcription in mouse macrophages. J Immunol 1997;159:5474-82.

21. Ho JL, Reed SG, Wick EA, Giordano M. Granulocyte-macrophage and macrophage colony-stimulating factors activate intramacrophage killing of Leishmania mexicana amazonensis. J Infect Dis 1990;162:224-30.

22. Liew FY, Li Y, Yang DM, Severn A, Cox FE. TNF-alpha reverses the disease-exacerbating effect of subcutaneous immunization against murine cutaneous leishmaniasis. Immunology 1991;74:304-9.

23. Heinzel FP, Schoenhaut DS, Rerko RM, Rosser LE, Gately MK. Recombinant interleukin-12 cures mice infected with Leishmania major. J Exp Med 1993;177:1505-9.

24. Murray HW, Hariprashad J. Interleukin 12 is effective treatment for an established systemic intracellular infection: experimental visceral leishmaniasis. J Exp Med 1995;181:387-91.

25. Murray HW, Cervia JS, Hariprashad J, Taylor AP, Stoeckle MY, Hockman H. Effect of granulocyte-macrophage colony-stimulating factor in experimental visceral leishmaniasis. J Clin Invest 1995;95:1183-92.

26. Hondowicz BD, Scharton-Kersten TM, Jones DE, Scott P. Leishmania major-infected C3H mice treated with anti-IL-12 $\mathrm{mAb}$ develop but do not maintain a Th2 response. J Immunol 1997;159:5024-31.

27. Ghalib HW, Whittle JA, Kubin M, et al. IL-12 enhances Th1-type responses in human Leishmania donovani infections. J Immunol 1995;154:4623-9.

28. Scharton TM, Scott P. Natural killer cells are a source of interferon gamma that drives differentiation of $\mathrm{CD} 4+\mathrm{T}$ cell subsets and induces early resistance to Leishmania major in mice. J Exp Med 1993;178:567-77.

29. Shu U, Kiniwa M, Wu CY, et al. Activated T cells induce interleukin-12 production by monocytes via CD40-CD40 ligand interaction. Eur J Immunol 1995;25:1125-8.

30. Campbell KA, Ovendale PJ, Kennedy MK, Fanslow WC, Reed SG, Maliszewski CR. CD40 ligand is required for protective cell-mediated immunity to Leishmania major. Immunity 1996;4:283-9

31. Kamanaka M, Yu P, Yasui T, et al. Protective role of $\mathrm{CD} 40$ in Leishmania major infection at two distinct phases of cell-mediated immunity. Immunity 1996:4:275-81.

32. Stout RD, Suttles J, Xu J, Grewal IS, Flavell RA. Impaired $\mathrm{T}$ cell-mediated macrophage activation in CD40 ligand-deficient mice. J Immunol 1996;156:8-11.

33. Muller I, Pedrazzini T, Kropf P, Louis J, Milon G. Establishment of resistance to Leishmania major infection in susceptible $\mathrm{BALB} / \mathrm{c}$ mice requires parasite-specific $\mathrm{CD} 8+\mathrm{T}$ cells. Int Immunol 1991;3:587-97.

34. Muller I, Kropf P, Etges RJ, Louis JA. Gamma interferon response in secondary Leishmania major infection: role of $\mathrm{CD} 8+\mathrm{T}$ cells. Infect Immun 1993:61:3730-8.

35. Huber M, Timms E, Mak TW, Rollinghoff M, Lohoff M. Effective and long-lasting immunity against the parasite Leishmania major in CD8-deficient mice. Infect Immun 1998;66:3968-70.

36. Sjolander A, Baldwin TM, Curtis JM, Handman E. Induction of a Th1 immune response and simultaneous lack of activation of a Th2 response are required for generation of immunity to leishmaniasis. J Immunol 1998;160:3949-57.

37. Handman E, Mitchell GF. Immunization with leishmania receptor for macrophages protects mice against cutaneous leishmaniasis. Proc Natl Acad Sci USA 1985;82:5910-4.

38. Scott P, Pearce E, Natovitz P, Sher A. Vaccination against cutaneous leishmaniasis in a murine model. Il. Immunologic properties of protective and nonprotective subfractions of soluble promastigote extract. J Immunol 1987;139:3118-25.

39. Gorczynski RM. Altered virulence and vaccination properties of Leishmania parasites grown in infected vaccinated mice. Infect Immun 1989;57:2430-3.

40. Nascimento E, Mayrink W, da Costa CA, et al. Vaccination of humans against cutaneous leishmaniasis: cellular and humoral immune responses. Infect Immun 1990;58:2198-203.

41. Armijos RX, Weigel MM, Aviles H, Maldonado R, Racines J. Field trial of a vaccine against New World cutaneous leishmaniasis in an at-risk child population: safety, immunogenicity, and efficacy during the first 12 months of follow-up. J Infect Dis 1998:177:1352-7.

42. Sharifi I, Fekri AR, Aflatonian MR, Nadim A, Nikian Y, Kamesipour A. Cutaneous leishmaniasis in primary school children in the south-eastern Iranian city of Bam, 1994-95. Bull World Health Organ 1998;76:289-93.

43. Bretscher PA, Wei G, Menon JN, Bielefeldt-Ohmann H. Establishment of stable, cell-mediated immunity that makes "susceptible" mice resistant to Leishmania major. Science 1992;257:539-42.

44. Menon JN, Bretscher PA. Parasite dose determines the Th1/Th2 nature of the response to Leishmania major independently of infection route and strain of host or parasite. Eur J Immunol $1998 ; 28: 4020-8$.

45. Muyombwe A, Olivier M, Harvie P, Bergeron MG, Ouellette M, Papadopoulou B. Protection against Leishmania major challenge infection in mice vaccinated with live recombinant parasites expressing a cytotoxic gene. J Infect Dis 1998;177:188-95.

46. Button LL, McMaster WR. Molecular cloning of the major surface antigen of leishmania. J Exp Med 1988;167:724-9.

47. Yang DM, Fairweather N, Button LL, McMaster WR, Kahl LP, Liew FY. Oral Salmonella typhimurium (AroA-) vaccine expressing a major leishmanial surface protein (gp63) preferentially induces $\mathrm{T}$ helper 1 cells and protective immunity against leishmaniasis. J Immunol 1990;145:2281-5.

48. McSorley SJ, Xu D, Liew FY. Vaccine efficacy of Salmonella strains expressing glycoprotein 63 with different promoters. Infect Immun 1997;65:171-8.

49. Mougneau E, Altare F, Wakil AE, et al. Expression cloning of a protective Leishmania antigen. Science 1995;268:563-6.

50. Melby PC, Sacks DL. Identification of antigens recognized by $\mathrm{T}$ cells in human leishmaniasis: analysis of T-cell clones by immunoblotting. Infect Immun 1989;57:2971-6.

51. Playfair JH, Blackwell JM, Miller HR. Modern vaccines. Parasitic diseases. Lancet 1990;335:1263-6.

52. Soong L, Duboise SM, Kima P, McMahon-Pratt D. Leishmania pifanoi amastigote antigens protect mice against cutaneous leishmaniasis. Infect Immun 1995;63:3559-66.

53. Xu D, Liew FY. Protection against leishmaniasis by injection of DNA encoding a major surface glycoprotein, gp63, of $L$ major. Immunology 1995;84:173-6.

54. Sedegah M, Hedstrom R, Hobart P, Hoffman SL. Protection against malaria by immunization with plasmid DNA encoding circumsporozoite protein. Proc Natl Acad Sci USA 1994;91:9866-70.

55. Tascon RE, Colston MJ, Ragno S, Stavropoulos E, Gregory D, Lowrie DB. Vaccination against tuberculosis by DNA injection. Nat Med 1996;2:888-92.

56. Gurunathan S, Sacks DL, Brown DR, et al. Vaccination with DNA encoding the immunodominant LACK parasite antigen confers protective immunity to mice infected with Leishmania major. J Exp Med 1997;186:1137-47.

57. Titus RG, Gueiros-Filho FJ, de Freitas LA, Beverley SM. Development of a safe live Leishmania vaccine line by gene replacement. Proc Natl Acad Sci USA 1995;92:10267-71.

58. Hubel A, Krobitsch S, Horauf A, Clos J. Leishmania major Hsp 100 is required chiefly in the mammalian stage of the parasite. Mol Cell Biol 1997; 17:5987-95.

59. Mottram JC, McCready BP, Brown KG, Grant KM. Gene disruptions indicate an essential function for the LmmCRK1 cdc2-related kinase of Leishmania mexicana. Mol Microbiol 1996;22:573-83

60. Mottram JC, Souza AE, Hutchison JE, Carter R, Frame MJ, Coombs GH. Evidence from disruption of the $l m c p b$ gene array of Leishmania mexicana that cysteine proteinases are virulence factors. Proc Natl Acad Sci USA 1996;93:6008-13.

61. Zhang WW, Matlashewski G. Loss of virulence in Leishmania donovani deficient in an amastigote-specific protein, A2. Proc Natl Acad Sci USA 1997;94:8807-11.

62. Fairlamb AH, Cerami A. Metabolism and functions of trypanothione in the kinetoplastida. Annu Rev Microbiol 1992;46:695-729.

63. Dumas C, Ouellette M, Tovar J, et al. Disruption of the trypanothione reductase gene of leishmania decreases its ability 
to survive oxidative stress in macrophages. EMBO I 1997:16:2590-8.

64. Cruz AK, Titus R, Beverley SM. Plasticity in chromosome number and testing of essential genes in Leishmania by targeting. Proc Natl Acad Sci USA 1993;90:1599-603.

65. Tovar J, Cunningham ML, Smith AC, Croft SL, Fairlamb AH. Down-regulation of Leishmania donovani trypanothione reductase by heterologous expression of a trans-dominant mutant homologue: effect on parasite intracellular survival. Proc Natl Acad Sci USA 1998;95:5311-6.

66. Gruber WC, Belshe RB, King JC, et al. Evaluation of live attenuated influenza vaccines in children 6-18 months of age: safety, immunogenicity, and efficacy. National Institute of Allergy and Infectious Diseases, Vaccine and Treatment Evaluation Program and the Wyeth-Ayerst ca Influenza Vaccine Investigators Group. J Infect Dis 1996;173:1313-9.

67. Meurice F, De Bouver JL, Vandevoorde D, Woods S, Bogaerts H. Immunogenicity and safety of a live attenuated varicella vaccine (Oka/SB Bio) in healthy children. J Infect Dis 1996;174(Suppl 3):S324-9.

68. Coster TS, Killeen KP, Waldor MK, et al. Safety, immunogenicity, and efficacy of live attenuated Vibrio cholerae 0139 vaccine prototype. Lancet 1995;345:949-52.

69. Kotloff KL, Noriega F, Losonsky GA, et al. Safety, immunogenicity, and transmissibility in humans of CVD 1203, a live oral Shigella flexneri 2 a vaccine candidate attenuated by deletions in aroA and virG. Infect Immun 1996;64:4542-8.

70. Guerin N, Teulieres L, Noba A, Schlumberger M, Bregere P, Chauvin P. Comparison of the safety and immunogenicity of the lyophilized Merieux seed and the World Health Organization working reference $\mathrm{BCG}$ vaccines in school-aged children in Senegal. Vaccine 1999;17:105-9

71. Guleria I, Teitelbaum R, McAdam RA, Kalpana G, Jacobs WR Jr, Bloom BR. Auxotrophic vaccines for tuberculosis. Nat Med 1996;2:334-7

72. Afonso LC, Scharton TM, Vieira LQ, Wysocka M, Trinchieri G, Scott $P$. The adjuvant effect of interleukin-12 in a vaccine against Leishmania major. Science 1994;263:235-7.

73. Maingon R, LeRay D, Hommel M. Leishmaniasis research and the European Union. Parasitol Today 1995;11:357-9.

74. Castes M, Blackwell J, Trujillo D, et al. Immune response in healthy volunteers vaccinated with killed leishmanial promastigotes plus BCG. I: Skin-test reactivity, T-cell proliferation and interferon-gamma production. Vaccine 1994:12:1041-51.

75. Fortier AH, Mock BA, Meltzer MS, Nacy CA. Mycobacterium bovis BCG-induced protection against cutaneous and systemic Leishmania major infections of mice. Infect Immun 1987:55:1707-14.

76. Wilson ME, Young BM, Andersen KP. A recombinant Leishmania chagasi antigen that stimulates cellular immune responses in infected mice. Infect Immun 1995;63:2062-9.

77. Russell DG, Alexander J. Effective immunization against cutaneous leishmaniasis with defined membrane antigens reconstituted into liposomes. J Immunol 1988;140:1274-9.

78. Kahl LP, Scott CA, Lelchuk R, Gregoriadis G, Liew FY. Vaccination against murine cutaneous leishmaniasis by using Leishmania major antigen/liposomes. Optimization and assessment of the requirement for intravenous immunization. J Immunol 1989;142:4441-9.
79. Scott P, Trinchieri G. IL-12 as an adjuvant for cell-mediated immunity. Semin Immunol 1997;9:285-91.

80. Frankenburg S, Axelrod O, Kutner S, et al. Effective immunization of mice against cutaneous leishmaniasis using an intrinsically adjuvanted synthetic lipopeptide vaccine. Vaccine 1996; 14:923-9.

81. Ferlin WG, von der Weid T, Cottrez F, Ferrick DA, Coffman RL, Howard MC. The induction of a protective response in Leishmania major-infected $\mathrm{BALB} / \mathrm{c}$ mice with anti-CD40 mAb. Eur J Immunol 1998;28:525-31.

82. Gonzalez CR, Noriega FR, Huerta S, et al. Immunogenicity of a Salmonella typhi CVD 908 candidate vaccine strain expressing the major surface protein gp63 of Leishmania mexicana mexicana. Vaccine $1998 ; 16: 1043-52$.

83. Handman E, Symons FM, Baldwin TM, Curtis JM, Scheerlinck JP. Protective vaccination with promastigote surface antigen 2 from Leishmania major is mediated by a TH1 type of immune response. Infect Immun 1995;63:4261-7.

84. Webb JR, Campos-Neto A, Ovendale PJ, et al. Human and murine immune responses to a novel Leishmania major recombinant protein encoded by members of a multicopy gene family. Infect Immun 1998;66:3279-89.

85. Walker PS, Scharton-Kersten T, Rowton ED, et al. Genetic immunization with glycoprotein 63 cDNA results in a helper T cell type 1 immune response and protection in a murine model of leishmaniasis. Hum Gene Ther 1998;9:1899-907.

86. Gurunathan S, Prussin C, Sacks DL, Seder RA. Vaccine requirements for sustained cellular immunity to an intracellular parasitic infection. Nat Med 1998;4:1409-15.

87. Xu D, McSorley SJ, Chatfield SN, Dougan G, Liew FY. Protection against Leishmania major infection in genetically susceptible BALB/c mice by gp63 delivered orally in attenuated Salmonella typhimurium (AroA-AroD-). Immunology 1995;85:1-7.

88. Soo SS, Villarreal-Ramos B, Anjam Khan CM, Hormaeche CE, Blackwell JM. Genetic control of immune response to recombinant antigens carried by an attenuated Salmonella typhimurium vaccine strain: Nramp1 influences T-helper subset responses and protection against leishmanial challenge. Infect Immun 1998;66:1910-7.

89. Xu D, McSorley SJ, Tetley L, et al. Protective effect on Leishmania major infection of migration inhibitory factor, TNF-alpha, and IFN-gamma administered orally via attenuated Salmonella typhimurium. J Immunol 1998; $160: 1285-9$

90. Connell ND, Medina-Acosta E, McMaster WR, Bloom BR, Russell DG. Effective immunization against cutaneous leishmaniasis with recombinant bacille Calmette-Guerin expressing the leishmania surface proteinase gp63. Proc Natl Acad Sci USA 1993;90:11473-7.

91. Abdelhak S, Louzir H, Timm J, et al. Recombinant BCG expressing the leishmania surface antigen gp63 induces protective immunity against Leishmania major infection in BALB/c mice. Microbiology 1995;141:1585-92.

92. McMahon-Pratt D, Rodriguez D, Rodriguez JR, et al. Recombinant vaccinia viruses expressing GP46/M-2 protect against Leishmania infection. Infect Immun 1993;61:3351-9

93. Tovar J, Wilkinson S, Mottram JC, Fairlamb AH. Evidence that trypanothione reductase is an essential enzyme in Leishmania by targeted replacement of the tryA gene locus. Mol Microbiol $1998 ; 29: 653-60$. 


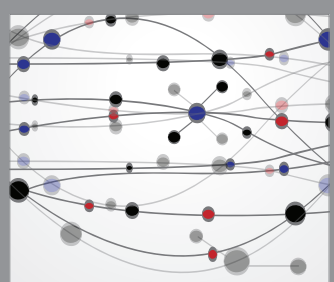

The Scientific World Journal
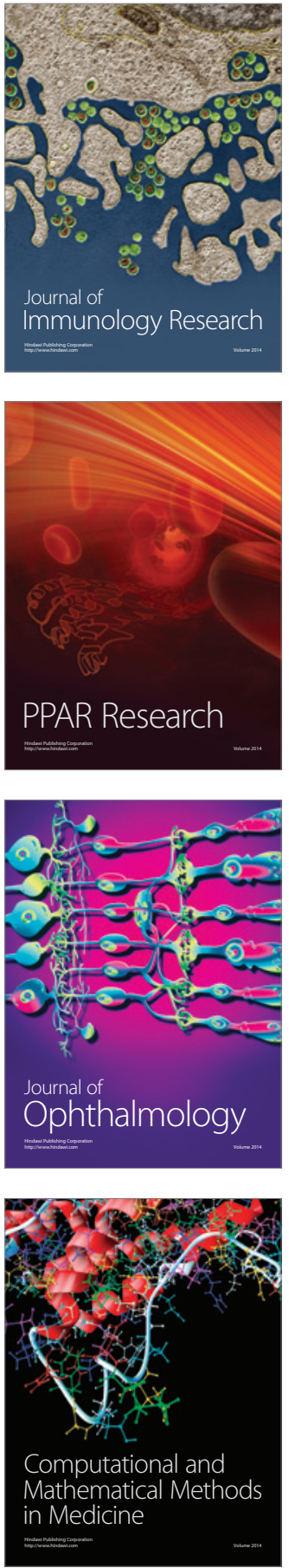

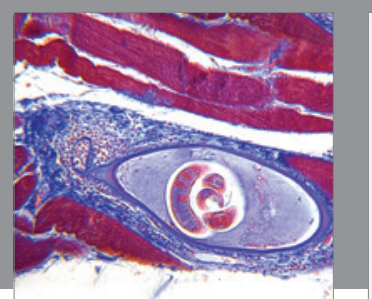

Gastroenterology Research and Practice

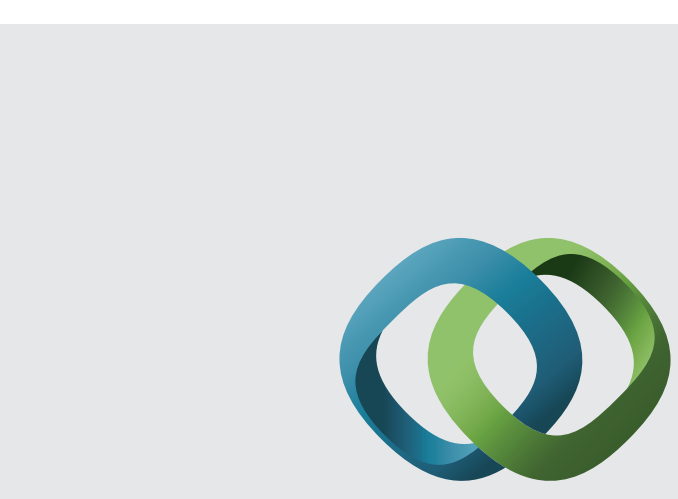

\section{Hindawi}

Submit your manuscripts at

http://www.hindawi.com
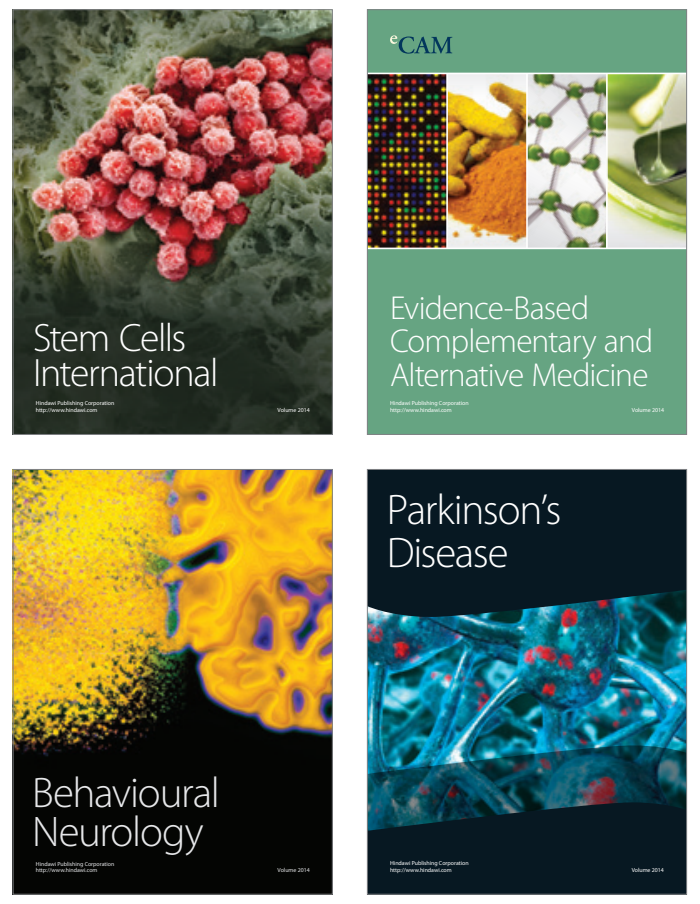
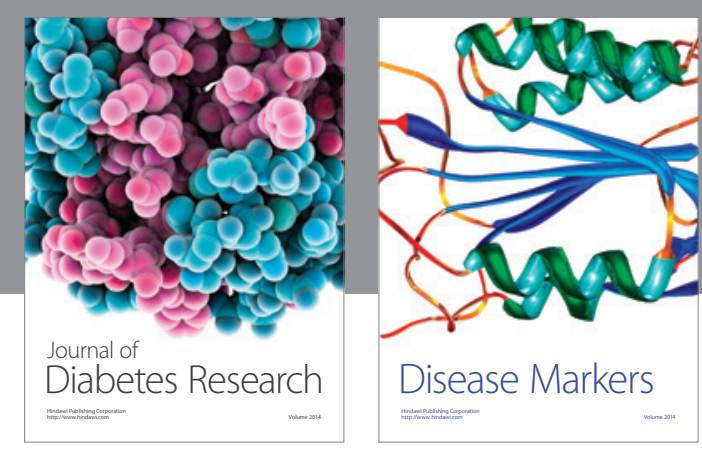

Disease Markers
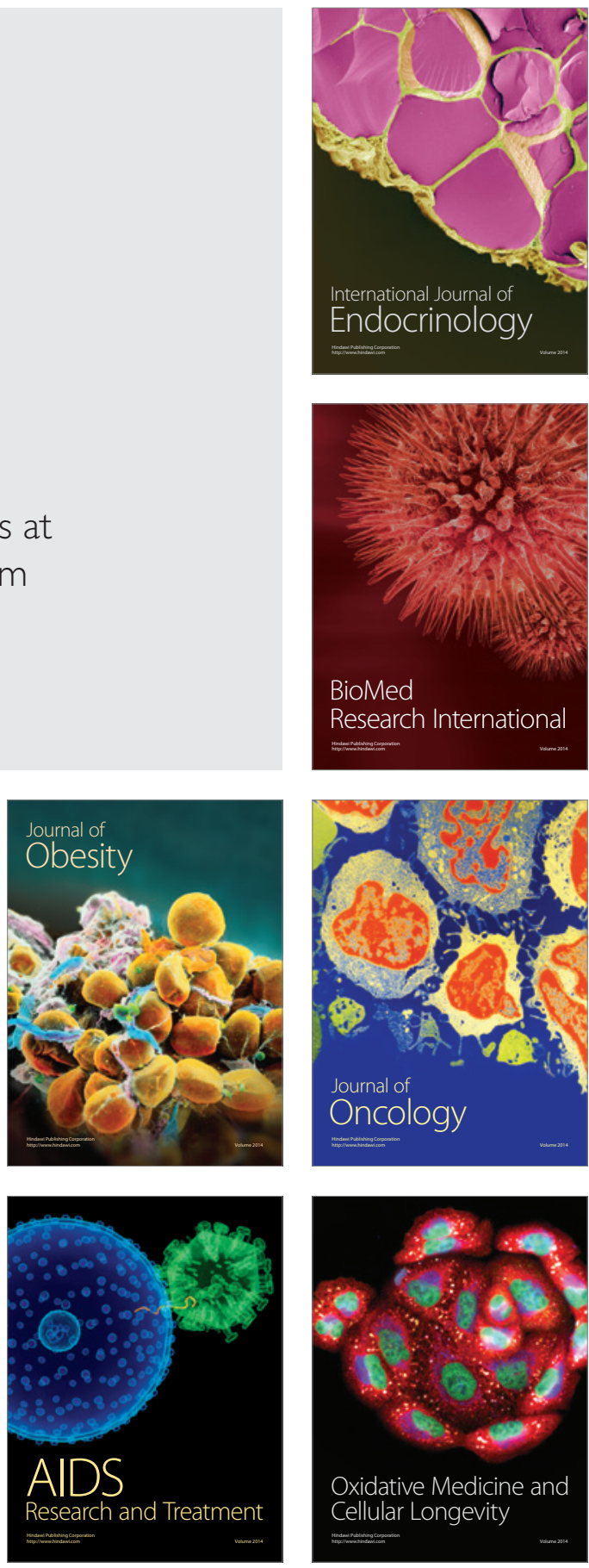